Article

\title{
The Influence of Light and Nutrient Starvation on Morphology, Biomass and Lipid Content in Seven Strains of Green Microalgae as a Source of Biodiesel
}

\author{
Lorenza Rugnini ${ }^{1}$, Catia Rossi ${ }^{1}$, Simonetta Antonaroli ${ }^{2}$,, Arnold Rakaj ${ }^{3}$ and Laura Bruno ${ }^{1, * \mathbb{D}}$ \\ 1 LBA-Laboratory of Biology of Algae, Department of Biology, University of Rome "Tor Vergata", \\ via Cracovia 1, 00133 Rome, Italy; rgnlnz01@uniroma2.it (L.R.); catia.red85@gmail.com (C.R.) \\ 2 Department of Chemical Sciences and Technologies, University of Rome "Tor Vergata", \\ via della Ricerca Scientifica 1, 00133 Rome, Italy; simonetta.antonaroli@uniroma2.it \\ 3 Laboratory of Experimental Ecology and Aquaculture, Department of Biology, University of Rome \\ “Tor Vergata", via Cracovia 1, 00133 Rome, Italy; arnoldrakaj@gmail.com \\ * Correspondence: laura.bruno@uniroma2.it; Tel.: +39-3383784941
}

Received: 20 July 2020; Accepted: 16 August 2020; Published: 18 August 2020

\begin{abstract}
The development of clean and renewable energy sources is currently one of the most important challenges facing the world. Although research interests in algae-based energy have been increasing in the last decade, only a small percentage of the bewildering diversity exhibited by microalgae has been investigated for biodiesel production. In this work, seven strains of green microalgae belonging to the genera Scenedesmus, Tetradesmus and Desmodesmus were grown in liquid medium with or without a nitrogen $(\mathrm{N})$ source- at two different irradiances $(120 \pm 20$ and $200 \pm$ $20 \mu \mathrm{mol}$ photons $\mathrm{m}^{-2} \mathrm{~s}^{-1}$ ) — to evaluate biomass production and FAME (fatty acid methyl esters) content for biodiesel production. The strains of Tetradesmus obliquus and Desmodesmus abundans grown in N-deprived medium showed the highest FAME content ( $22.0 \%$ and $34.6 \%$, respectively); lipid profile characterization highlighted the abundance of saturated FAME (as C16:0 and C18:0) that favors better viscosity (flow properties) and applicability of biodiesel at low temperatures. Light microscopy and confocal laser scanning microscopy observations were employed as a fast method to monitor the vital status of cells and lipid droplet accumulation after Nile red staining in different culture conditions.
\end{abstract}

Keywords: Scenedesmus; Tetradesmus; Desmodesmus; FAME; biodiesel; CLSM; Nile red; microalgae

\section{Introduction}

The energy requirements of the transport sector are growing worldwide. Hence, there is a continuous increase in the demand for fuel. In addition, the pollution problems and the impact on the environment of the use of fossil fuels have highlighted the need for alternative energy sources. Development of sustainable, clean and renewable energy sources is, therefore, currently one of the most daunting challenges facing the world. Today, $90 \%$ of global energy demand is fulfilled by fossil fuels, which are on the verge of depletion and can be replaced by viable alternatives, such as biofuels $[1,2]$ that could be capable of reducing the petroleum requirement [3]. Photosynthetic microalgae are able to accumulate up to $60-70 \%$ of lipids, mostly as triacylglycerols (TAGs) that can be converted into biodiesel via a simple transesterification process [4,5]. Algae biodiesel contains no sulfur and performs as well as petroleum diesel, while reducing emissions of particulate matter, $\mathrm{CO}$, hydrocarbons and $\mathrm{SOx}$ [6]. Fatty acid composition is an important factor to consider in the successful generation of biodiesel from algae. The selection of suitable strains of green microalgae that combine high growth rate, good 
biomass productivity, high lipid content and resistance to stress conditions still remains a challenge for large-scale cultivation and biodiesel production.

Various studies of microalgae have demonstrated that lipid productivity could be altered by several different factors, such as carbon dioxide levels, temperature, light intensity, nutrient concentrations, metal/ion stress [7-9]. Light intensity is an important parameter as it has been shown to drastically affect the growth of microalgae and their lipid content: low and high light intensity have been shown to cause unfavorable growth in different species of microalgae, low irradiance induces the formation of polyunsaturated fatty acids (PUFAs) whereas high intensity decreases total polar lipid content [4,10-12]. Several studies have demonstrated that nitrogen $(\mathrm{N})$ limitation, even if it slows down the cell growth and development, is the most effective strategy for the production and accumulation of lipids; when $\mathrm{N}$ is limited, the proportion of saturated fatty acids (SFAs) and monounsaturated fatty acids (MUFAs) increase and the proportion of polyunsaturated fatty acids (PUFAs) decreases with respect to total lipids [12-14]. To date, routine protocols for lipid accumulation in microalgae recommend a two-phase culturing system: first, microalgae are grown in optimized nutritional conditions for maximum biomass production, after which cultures are subjected to nutrient starvation (especially nitrogen), light irradiance variation or the presence of heavy metals to achieve high lipid content in cells.

The Scenedesmus and Desmodesmus genera are considered ideal microalgal species for biodiesel production due to their high lipid yield and good adaptability-allowing them to grow in different conditions [15]. This study therefore aims to study the effect of two different light irradiance and $\mathrm{N}$ deprivation on biomass and lipid production of seven different green strains of microalgae. Strains showing the highest lipid yield were studied in detail, evaluating lipid profile and biodiesel properties that are fundamentally to the success of the algae-based biodiesel industry, in addition to its yields [16]. Few studies have focused on the effects of light intensity combined with $\mathrm{N}$ limitation on fatty acid composition. Cell morphology and lipid accumulation were also studied through microscopy observations as a fast tool to analyze the vital status of cells and lipid accumulation. The results illustrated here, will be fundamental for the selection and growth optimization of the most suitable strain of microalgae for the successful production of algae-based biodiesel.

\section{Materials and Methods}

\subsection{Microalgae Strains}

A total of seven strains (Chlorophyceae) were employed in this study. Scenedesmus acuminatus 38.81, S. obliquus $276.3 \mathrm{~d}$ and S. rubescens 5.95 were supplied by the Culture Collection of Algae at the University of Göttingen, Germany (SAG), while a strain of Tetradesmus obliquus, previously known as Scenedesmus sp. [17] was isolated from the primary filter of a water purification system and stored in the 'Vergata Rome University Culture collection' (VRUC) [18]. Desmodesmus communis 276-48 and D. opoliensis 64.94 were also obtained from SAG collection, while D. abundans 283/1.8 was from ACUF (Algal Collection University Federico II). The strains were acclimated in liquid bold basal medium (BBM) [19] for one month $(25 \mathrm{~mL}$ in $50-\mathrm{mL}$ flasks), under a condition of $120 \mu$ mol photons $\mathrm{m}^{-2} \mathrm{~s}^{-1}, 20 \pm 2{ }^{\circ} \mathrm{C}$, relative humidity of $50 \%$ and at light-dark regime of $12: 12 \mathrm{~h}$.

\subsection{Experimental Setup}

In a first run, cultures were transferred into a 1-L Erlenmeyer flask containing $400 \mathrm{~mL}$ of fresh BBM medium ( $2.5 \%$ inoculum) and bubbled with sterilized-filtered air. Growth conditions were the same as those reported above, testing two different irradiances: $120 \pm 20 \mu \mathrm{mol}$ photons $\mathrm{m}^{-2} \mathrm{~s}^{-1}\left(\mathrm{~L}_{120}\right)$ and 200 $\pm 20 \mu \mathrm{mol}$ photons $\mathrm{m}^{-2} \mathrm{~s}^{-1}\left(\mathrm{~L}_{200}\right)$. At the stationary phase, all algal cultures were divided into two aliquots of the same volume (second run) and cells were removed from the medium by centrifugation for $25 \mathrm{~min}$ at $19,200 \times \mathrm{g}$ and $36,000 \times \mathrm{g}$ for Scenedesmus, Tetradesmus and Desmodesmus strains, respectively. After this, the two pellets obtained for each strain were transferred into $400 \mathrm{~mL}$ of BBM with a nitrogen source $(B B M+N)$ and in $400 \mathrm{~mL}$ of $B B M$ without a nitrogen source $(B B M-N)$ and exposed again at $\mathrm{L}_{120}$ 
and $\mathrm{L}_{200}\left(\mathrm{BBM}+\mathrm{N} / \mathrm{L}_{120}\right.$ and $\mathrm{BBM}-\mathrm{N} / \mathrm{L}_{200}$ growing conditions) until the stationary phase of the second run. All experiments were conducted in triplicates.

\subsection{Analytical Methods}

Optical density (OD) and dry weight (DW) were measured to follow microalgal growth in both runs. OD was performed at $560 \mathrm{~nm}\left(\mathrm{OD}_{560}\right)$ using a spectrophotometer (Varian Cary 50 Bio UV-Visible spectrophotometer). DWs of the biomass were obtained by filtering the samples through preweighed filters (Whatman GF/C) and then drying them at $104{ }^{\circ} \mathrm{C}$ for $24 \mathrm{~h}$ before reweighing, to calculate biomass production as $\mathrm{gDW} \mathrm{L}{ }^{-1}$. Biomass productivity $\left(\mathrm{gDW} \mathrm{L}^{-1} \mathrm{day}^{-1}\right)$ was calculated by dividing the difference between the dry weights (DWs) at the end and at the start of the experiment by its duration in days, for each run and each tested condition (BBM+N/L 120 and BBM-N/L $\left./ \mathrm{L}_{200}\right)$. At the end of each experiment, cultures were centrifuged and dried to detect biomass DW expressed in grams.

\subsection{Lipid Extraction and Fatty Acid Profile Characterization}

For lipid extraction, cells were collected by centrifugation for $25 \mathrm{~min}$ at $19,200 \times g$ and $36,000 \times g$ for Scenedesmus, Tetradesmus and Desmodesmus strains, respectively and dried at $65{ }^{\circ} \mathrm{C}$ for $24 \mathrm{~h}$. Then, biomass obtained by the strains of S. acuminatus, S. obliquus, S. rubescens and T. obliquus was treated for 5 min with $10 \mathrm{~mL}$ of $\mathrm{HClO}_{4}$ at $0{ }^{\circ} \mathrm{C}$; biomass from D. abundans, D. communis, D. opoliensis was treated for $1 \mathrm{~h}$ with $10 \mathrm{~mL}$ of $\mathrm{HClO}_{4}$ at $0{ }^{\circ} \mathrm{C}$. The difference in the time of exposure to $\mathrm{HClO}_{4}$ was due to the presence of three sporopollenin wall layers in Scenedesmus species and four in Desmodesmus species. After acid treatments, samples were centrifuged at $5000 \times \mathrm{g}$ for $5 \mathrm{~min}$ and lipids were extracted by incubating the cells with $15 \mathrm{~mL}$ of a mixture made of $\mathrm{CHCl}_{3} / \mathrm{MeOH}(2 / 1, v / v)$ for 24 and $48 \mathrm{~h}$ for Scenedesmus, Tetradesmus and Desmodesmus strains, respectively. Then, the obtained organic layer was separated by funnel separation phase, rinsed with water and brine (saturated $\mathrm{NaCl}$ solution), and the solvents employed were recovered by rotary evaporation.

The transesterification procedure of lipids to fatty acid methyl esters (FAME) was conducted by boiling $5 \mathrm{~mL}$ of crude lipids with $1 \mathrm{~mL}$ of MeONa in $0.25 \mathrm{M}$ of MeOH/diethyl ether $(1: 1, v / v)$, following Bannon et al. [20]. Then, $5 \mathrm{~mL}$ of brine and $3 \mathrm{~mL}$ of hexane/diethyl ether $(1: 1, v / v)$ were added and mixed for $10 \mathrm{~min}$ at $50{ }^{\circ} \mathrm{C}$. FAME were then obtained by funnel separation from the organic layer and the FAME profile was determined by gas chromatograph (Varian CP3800) equipped with a split injector and fitted with a fused silica capillary column Supelco SLB-5ms. The standard and the samples $(1.0 \mu \mathrm{L})$ were injected into the column, with a temperature program starting from $100{ }^{\circ} \mathrm{C}$ for $2 \mathrm{~min}$, increased by $5{ }^{\circ} \mathrm{C} / \mathrm{min}$ to $240{ }^{\circ} \mathrm{C}$ final (split/column flow ratio, 1:40). The FAME content was estimated as the percentage of esterified lipids per gram of dry biomass.

\subsection{Evaluation of Biodiesel Properties}

Biodiesel qualities and properties are quantified through standard parameters such as SV (saponification value), IV (iodine value), CN (cetane number), CFPP (cold filter plugging point), degree of unsaturation (DU) and oxidation stability. These parameters were calculated using the empirical Equations (1)-(4) previously reported [8]:

$$
\begin{gathered}
\mathrm{SV}=\sum\left(\frac{560 * N}{M}\right) \\
\mathrm{IV}=\sum\left(\frac{254 * N D}{M}\right) \\
\mathrm{CN}=46.3+\left(\frac{5458}{S V}\right)-(0.225 * \mathrm{IV}) \\
\mathrm{CFPP}=(3.1417 * L C S F)-16.477
\end{gathered}
$$


where $\mathrm{N}$ is the percentage of each FA component, $\mathrm{M}$ is the FA molecular mass, $\mathrm{D}$ is the number of double bonds, and LCSF is the long-chain saturated factor calculated trough Equation (5):

$$
\operatorname{LCSF}=\left(0.1 \times \mathrm{C}_{16}\right)+\left(0.5 \times \mathrm{C}_{18}\right)+\left(1 \times \mathrm{C}_{20}\right)+\left(2 \times \mathrm{C}_{24}\right)
$$

The DU was calculated based on Equation (6), as the amount of MUFA and PUFA present in the microalgae oil.

$$
\mathrm{DU}=\mathrm{MUFA}+2 \times(\mathrm{PUFA})
$$

\subsection{Microscopy}

Morphologic investigations were performed using a light microscope (Zeiss Axioskop; Carl Zeiss, Inc., Thornwood, New York, NY, USA) equipped with a device for differential contrast. Images were acquired using a digital camera NIKON COOLPIX 995. For each strain of the selected Scenedesmus, Tetradesmus and Desmodesmus genera grown at $\mathrm{L}_{120}$ and $\mathrm{L}_{200}$, with or without $\mathrm{N}$-source, cell morphology was analyzed taking fifty measurements by Image image analysis software [21]. Lipid droplet accumulation was also observed over the time in the strain of $D$. abundans grown under the different culture conditions. After Nile red staining $\left(100 \mu \mathrm{g} \mathrm{mL}^{-1}\right)$ [22], cells were observed by confocal laser scanning microscope (CLSM; Olympus FV1000) using excitation at 488 and $635 \mathrm{~nm}$ and two channels for detecting chlorophyll a (650-750-nm emission range) and lipid labeled by Nile red $($ maximum emission $=572 \mathrm{~nm})$. Three-dimensional images were constructed from series of $2 \mathrm{D}$ cross-sectional images ( $\mathrm{x}-\mathrm{y}$ plane) that were captured at $0.5-\mu \mathrm{m}$ intervals along the $z$-axis using IMARIS 6.2.0 software (Bitplane AG, Zurich, Switzerland). The regions of interest (ROI) were evaluated in order to perform a spectral analysis in all the visible wavelength regions.

\subsection{Statistical Analysis}

All experiments were performed in triplicates. Principal component analysis (PCA) was performed to evaluate the relationships among the observations (strains in all culture conditions) and the variables: biomass yield, biomass production, lipid yield and FAME. PCA was performed on a correlation matrix with PAST software, version 4.0 [23] and other datasets were processed with GraphPad Prism Software, version 8.0 (San Diego, CA, USA).

\section{Results and Discussion}

\subsection{Growth Evaluation and Biomass Productivity}

Growth curves according to $\mathrm{OD}_{560}$ measurements for both runs of all the seven strains are reported in Supplementary Materials (Figures S1 and S2). The cultures showed an exponential phase between 7 and 10 days in complete medium; after the division in two aliquots, the growth in the culture without a nitrogen source was significantly different respect to the ones in the complete medium $(p<0.05)$, although a minimum level of growth was still registered in all the strains tested for around 10-13 days. Biomass productivity of the cultures of S. acuminatus, S. obliquus, S. rubescens, T. obliquus, D. abundans, D. communis, D. opoliensis obtained in the first run (Figure 1) and, consecutively, in the second run for all the culture conditions tested was evaluated. For all the strains, the biomass productivity was higher in cultures grown at $\mathrm{L}_{200}(p<0.05)$ than $\mathrm{L}_{120}$ conditions, in line with data reported by Sforza et al. [24] for S. obliquus grown at light irradiance from 10 to $150 \mu \mathrm{mol}$ photons $\mathrm{m}^{-2}$ $\mathrm{s}^{-1}$ that obtained the highest growth rate at the maximum light intensity tested. Nzayisenga et al. (2020) [4] demonstrated that the highest biomass production for Chlorella vulgaris, Ettlia pseudoalveolaris and S. obliquus was at $150 \mu \mathrm{mol}$ photons $\mathrm{m}^{-2} \mathrm{~s}^{-1}$ and at $300 \mu \mathrm{mol}$ photons $\mathrm{m}^{-2} \mathrm{~s}^{-1}$ for Desmodesmus sp, while the lowest production was at $50 \mu \mathrm{mol}$ photons $\mathrm{m}^{-2} \mathrm{~s}^{-1}$ for all species, as reported in our study. 


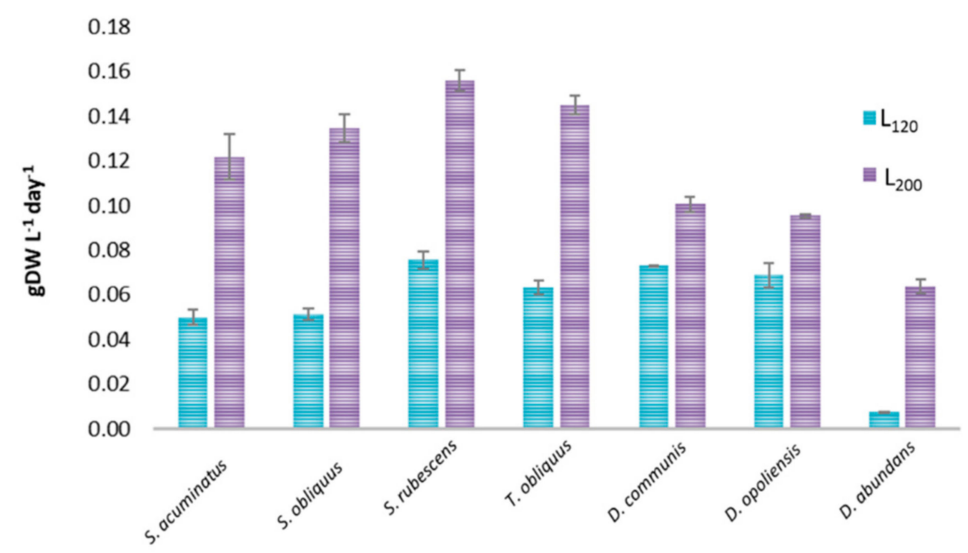

Figure 1. Biomass productivity $\left(\mathrm{gDW} \mathrm{L}^{-1} \mathrm{day}^{-1}\right)$ obtained during the first run for all the strains employed in this study at the two different irradiances (values are means of 3 measurements \pm standard deviation).

The effect of nitrogen starvation on the increase in lipid content was evaluated by dividing all cultures in two subcultures, with or without a N-source. Regarding the biomass productivity in this second run (Figure 2), the strain of $S$. rubescens showed the highest values in both culture conditions, particularly at $\mathrm{L}_{200}\left(0.930 \pm 0.004 \mathrm{gDW} \mathrm{L}^{-1}\right.$ in BBM+N/L $\mathrm{L}_{120}$ and $0.980 \pm 0.003$ in $\mathrm{BBM}+\mathrm{N} / \mathrm{L}_{200}$, respectively), greater than that obtained among all the strains tested. To evaluate the effect of light and N-source on biomass production and productivity, samples were compared by ANOVA, followed by the Tukey's multiple comparisons test. Data showed that, in these conditions, there was no significant difference for cultures grown at $\mathrm{L}_{120}$ with respect to those grown at $\mathrm{L}_{200}(p>0.05)$, but biomass productivity was significantly affected by nitrogen source $(p<0.001)$. Biomass productivity in all Scenedesmus and Tetradesmus strains was from two to 10 times higher in the complete BBM medium $(\mathrm{BBM}+\mathrm{N})$ than in $\mathrm{BBM}-\mathrm{N}$ in $\mathrm{L}_{120}$ and up to 32 times higher when grown in $\mathrm{L}_{200}$ conditions for S. acuminatus. The presence of a $\mathrm{N}$-source in $\mathrm{BBM}$, also affected the growth of $D$. abundans, that was 5 times greater in $\mathrm{BBM}+\mathrm{N} / \mathrm{L}_{200}$ than $\mathrm{BBM}-\mathrm{N} / \mathrm{L}_{200}$.
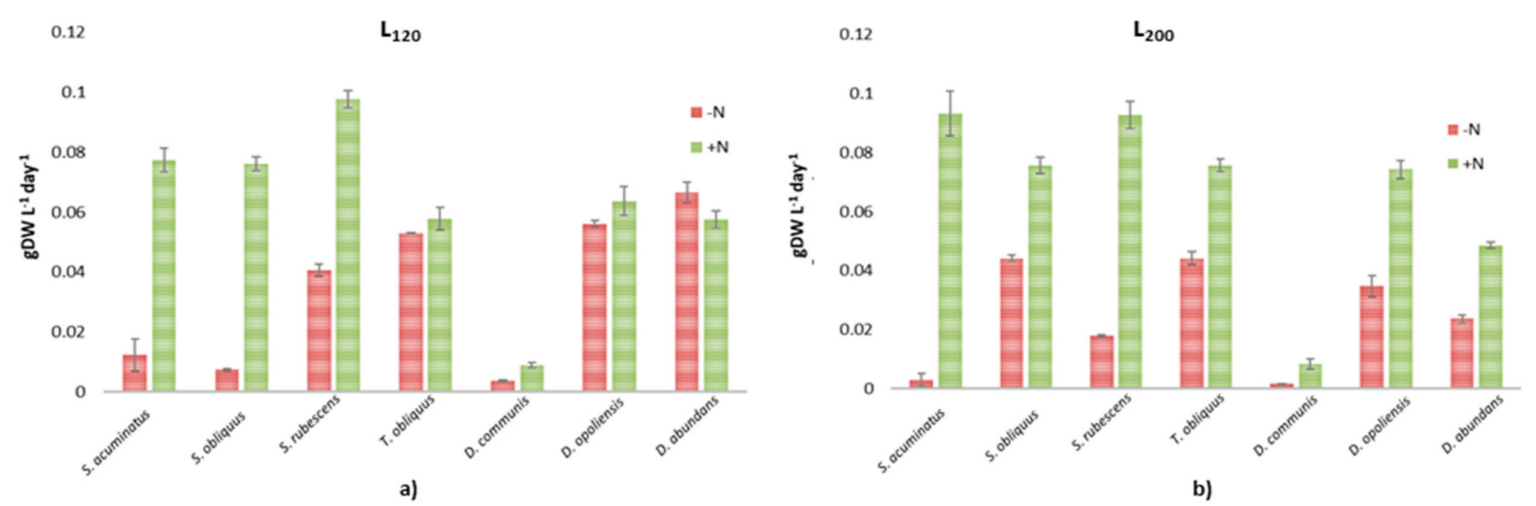

Figure 2. Biomass productivity, as grams of dry weight for liters for day, obtained for the seven strains grown at (a) $120 \pm 20 \mu \mathrm{mol}$ photons $\mathrm{m}^{-2} \mathrm{~s}^{-1}\left(\mathrm{~L}_{120}\right)$ and (b) $200 \pm 20 \mu \mathrm{mol}$ photons $\mathrm{m}^{-2} \mathrm{~s}^{-1}\left(\mathrm{~L}_{200}\right)$ with $(+\mathrm{N})$ and without $(-\mathrm{N})$ a nitrogen source.

Thus, all the Scenedesmus, Tetradesmus and Desmodesmus strains tested in this study showed that the best growth conditions among the ones tested, can be represented by complete BBM and an exposure to $200 \pm 20 \mu \mathrm{mol}$ photons $\mathrm{m}^{-2} \mathrm{~s}^{-1}$. 


\subsection{Lipid Yield and FAME Characterization}

Many stress factors have been shown to affect biomass productivity in different species of microalgae and thus lipid accumulation, such as $\mathrm{N}$ and $\mathrm{P}$ limitation, light irradiance and the presence of heavy metals $[17,25,26]$. For many species of microalgae, it has been established that N-deprivation correlates positively with lipid accumulation which in turn may result in a lower biomass yield. Thus, it is a good practice to produce biomass in optimal culture conditions for the species under study and then apply the stress factor to increase lipid content. In this study, biomass production and FAME yield obtained for all the strains of Scenedesmus, Tetradesmus and Desmodesmus under the selected growth conditions, are reported in Table 1. After lipid extraction and transesterification, FAME obtained were quantified and characterized. FAME yields in BBM-N were significantly higher than in BBM $+\mathrm{N}$ $(p<0.05)$. In general, Desmodesmus strains showed higher production of FAME than Scenedesmus and Tetradesmus strains, up to $34.60 \%$ in D. abundans when grown in BBM-N/L200, while T. obliquus sp. and $S$. rubescens had the highest FAME yields when grown in BBM-N/L 120 .

Table 1. Biomass production (in terms of $\mathrm{gDW} \mathrm{L}^{-1}$ ) and fatty acid methyl esters (FAME) yields (as percentage, \%) obtained both for Scenedesmus, Tetradesmus and Desmodesmus strains in different culture conditions (BBM=bold basal medium).

\begin{tabular}{|c|c|c|c|c|c|c|c|c|}
\hline & & S. acuminatus & S. obliquus & S. rubescens & T. obliquus & D. abundans & D. communis & D.opoliensis \\
\hline \multirow{2}{*}{ BBM-N/L120 } & $\mathrm{gDW} \mathrm{L}^{-1}$ & $0.08 \pm 0.00$ & $0.05 \pm 0.02$ & $0.36 \pm 0.01$ & $0.37 \pm 0.01$ & $0.52 \pm 0.05$ & $0.62 \pm 0.03$ & $0.73 \pm 0.01$ \\
\hline & FAME (\%) & 4.56 & 13.01 & 18.80 & 22.26 & 22 & 8.67 & 23.00 \\
\hline $\mathrm{BBM}+\mathrm{N} / \mathrm{L}_{120}$ & FAME (\%) & 6.60 & 8.37 & 16.13 & 11.52 & 10.51 & 16.29 & 3.53 \\
\hline \multirow{2}{*}{ BBM-N/L 200} & $\mathrm{gDW} \mathrm{L}^{-1}$ & $0.02 \pm 0.01$ & $0.35 \pm 0.02$ & $0.14 \pm 0.01$ & $0.35 \pm 0.01$ & $0.27 \pm 0.01$ & $0.42 \pm 0.02$ & $0.28 \pm 0.01$ \\
\hline & FAME (\%) & 16.88 & 7.04 & 11.92 & 14.79 & 34.60 & n.d. & 25.10 \\
\hline $\mathrm{BBM}+\mathrm{N} / \mathrm{L}_{200}$ & FAME (\%) & 12.24 & 14.34 & 8.34 & 8.85 & 17.88 & 3.93 & 13.75 \\
\hline
\end{tabular}

Biodiesel quality is related to fatty acid (FA) composition and is determined by the degree of saturation of the fatty acid. In this study, FAME characterization was conducted on the microalgal strains that showed the highest FAME yields, T. obliquus and D. abundans, being the most interesting, at all the culture conditions tested (Table 2). GC profiles showed that saturated fatty acids (SFAs) were over $90 \%$ of total FAME, in T. obliquus and D. abundans grown in BBM-N/L 120 and BBM+N/L 200 , respectively. The ideal FAME component for good quality biodiesel should be rich in palmitic (C16:0) and stearic acids (C18:0): a high percentage of saturated FAME favors better viscosity (flow properties) and the applicability of biodiesel at low temperatures [27]. In this study, C16:0 and C18:0 were detected in all culture conditions in both strains, with a percentage of up to 81\% for C16:0 and 15\% for C18:0. These fatty acids are present in all cyanobacteria and in many other microalgae studied to date [28-30], in addition to being recognized as the most interesting for the production of biodiesel. Between monounsaturated FAME (MUFA), gadoleic acid (C20:1) was the most abundant for T. obliquus grown in BBM+N/L 120 (about $21 \%$ ) and for D. abundans in BBM-N/L 120 (over $40 \%$ ). Long chain saturated and MUFA are suitable for biodiesel, as they improve oxidative stability without greatly affecting its cold flow properties [8,31], while the reactive sites of polyunsaturated fatty acids (PUFA) are susceptible for free radical attack and, in high quantities, negatively affect the oxidative stability of biodiesel [32]. Linolelaidic and linoleic acid (C18:2 and C18:3), were both found in a percentage higher than $10 \%$ in D. abundans in BBM+N/L 120 , while PUFA with more than 4 double bonds never exceed $1 \%$ (according to the European standard EN 14,214 [33]), except for D. abundans in BBM-N/L200.

Comparing the biodiesel properties obtained here with the European biodiesel (EN 14214) and American biodiesel standards (ASTM D 6751-08) [34], CN of cultures grown in absence of N, both at $\mathrm{L}_{120}$ and $\mathrm{L}_{200}$, were in accordance with the requirements of US standards, that requires $\mathrm{CN}>37$ and IV $<120$ (detected in all culture conditions for both species) for good biodiesel quality. A high $\mathrm{CN}$ value is an indicator of better combustion and low nitrous oxide emissions, the IV is used to 
determine the degree of unsaturation of biodiesel oil. The ratio between unsaturated fatty acids (UFAs) and saturated fatty acids (SFAs) is crucial for the evaluation of biodiesel physical properties. Here, the smallest ratio UFAs/SFAs between the tested conditions was measured in Scenedesmus sp. in $\mathrm{BBM}-\mathrm{N} / \mathrm{L}_{120}$ and D. abundans in BBM-N/L 200 (UFAs/SFAs $=0.07$ ), indicating a high percentage of SFAs that are responsible for resistance to degradation and oxidation, improving shelf life $[35,36]$. Degree of unsaturation (DU) influences the oxidative stability of biodiesel and it is the sum of the masses of MUFA and PUFA. EN 14,214 and ASTM D6751-08 have not mentioned the value of DU, but it influences the IV of biodiesel that should be $<120$ [32]. Except for D. abundans in BBM+N/L 120 , the IV values calculated in this study are in accordance with the European and American standards for both species in all the culture conditions.

Table 2. FAME profile of the two green microalgae that showed the highest lipid yields in different culture conditions.

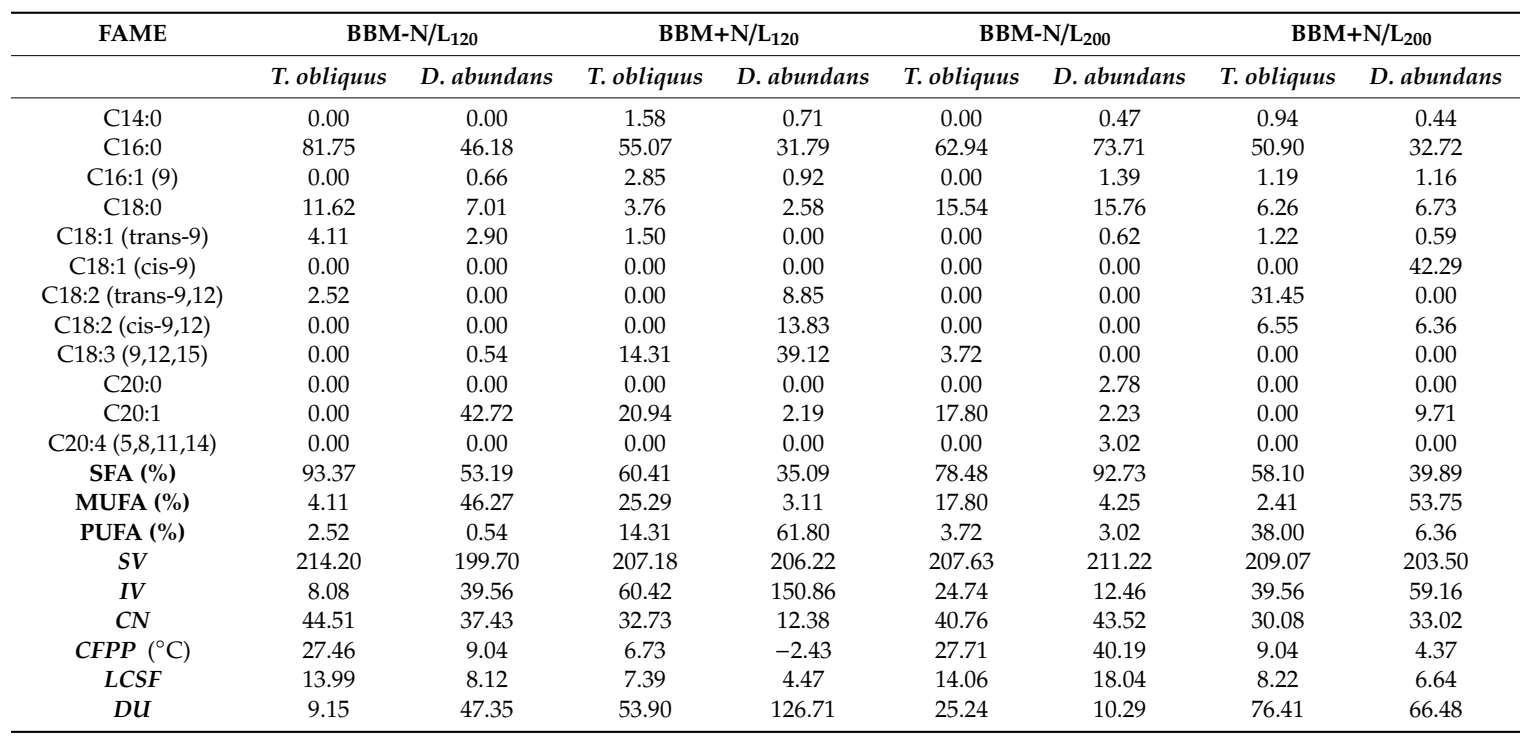

\subsection{Microscopy Observations}

When culturing microalgae, for biodiesel production, the availability of a quick method to monitor the status of the culture could be a useful and cost-saving tool. Thus, in the present study we monitored the cell morphology and the lipid accumulation by using light and confocal laser scanning microscopes. Light microscopy (LM) observations were carried out for all the strains investigated at the start of the experiment and during the stationary phase of growth (between 10th and 13th day) to evaluate any significant variations in cell size and morphology depending on the different culture conditions (Table 3).

The deprivation of a nitrogen source induced a variation of the cell size at the stationary phase, with the highest increase in cell length size in S. acuminatus (from $20.55 \pm 2.51 \mu \mathrm{m}$ at the initial phase to $24.49 \pm 2.90$ at stationary phase), D. abundans (from $6.71 \pm 1.54 \mu \mathrm{m}$ to $8.13 \pm 1.27 \mu \mathrm{m}$ ) and D. opoliensis (from $21.55 \pm 1.88 \mu \mathrm{m}$ to $29.07 \pm 1.69 \mu \mathrm{m}$ ). Various studies have shown that the genera Scenedesmus, Tetradesmus and Desmodesmus are pleomorphic with high morphologic plasticity. All genera are able to produce unicells and/or coenobia under various environmental conditions (e.g., length of photoperiod, $\mathrm{pH}$, nutrients, etc.) and in response to predators [37-39]. Pancha et al. [13] observed a change in cell size of Scenedesmus sp. CCNM 1077 when grown in nitrate starved conditions, from $4.5 \mu \mathrm{m}$ in complete medium to around $5.3 \mu \mathrm{m}$ after 15 days of $\mathrm{N}$-deprivation, around $16 \%$ greater than control, as for S. acuminatus and D. abundans in this study. Cell sizes of D. opoliensis grown in BBM-N showed a $25 \%$ increase compared with $\mathrm{BBM}+\mathrm{N}$, like the results reported for $\mathrm{N}$-deprived Nannochloropsis sp. and Chlorococcum sp. cells by Yap et al. [40] that were approx. 25\% bigger than the N-replete cells. 
Table 3. Evaluation of cell length for all strains in the tested conditions, measured at the initial phase of the experiment and at the stationary phase. Values are means of fifty measures \pm standard deviations.

\begin{tabular}{|c|c|c|c|}
\hline & \multirow[t]{2}{*}{ Growth Conditions } & \multicolumn{2}{|c|}{ Length $(\mu \mathrm{m})$} \\
\hline & & Initial Phase & Stationary Phase \\
\hline \multirow{4}{*}{ S. acuminatus } & BBM-N/L 120 & $20.55 \pm 2.51$ & $24.49 \pm 2.90$ \\
\hline & $\mathrm{BBM}+\mathrm{N} / \mathrm{L}_{120}$ & $19.68 \pm 4.22$ & $25.45 \pm 3.09$ \\
\hline & $\mathrm{BBM}-\mathrm{N} / \mathrm{L}_{200}$ & $26.58 \pm 3.71$ & $26.75 \pm 2.64$ \\
\hline & $\mathrm{BBM}+\mathrm{N} / \mathrm{L}_{200}$ & $25.72 \pm 3.91$ & $26.03 \pm 3.92$ \\
\hline \multirow{4}{*}{ S. obliquus } & $\mathrm{BBM}-\mathrm{N} / \mathrm{L}_{120}$ & $12.69 \pm 1.95$ & $13.41 \pm 3.18$ \\
\hline & $\mathrm{BBM}+\mathrm{N} / \mathrm{L}_{120}$ & $15.05 \pm 2.21$ & $13.46 \pm 2.58$ \\
\hline & $\mathrm{BBM}-\mathrm{N} / \mathrm{L}_{200}$ & $18.02 \pm 2.83$ & $14.73 \pm 4.06$ \\
\hline & $\mathrm{BBM}+\mathrm{N} / \mathrm{L}_{200}$ & $16.22 \pm 2.61$ & $17.14 \pm 4.30$ \\
\hline \multirow{4}{*}{ S. rubescens } & $\mathrm{BBM}-\mathrm{N} / \mathrm{L}_{120}$ & $12.04 \pm 2.18$ & $11.83 \pm 2.36$ \\
\hline & $\mathrm{BBM}+\mathrm{N} / \mathrm{L}_{120}$ & $12.07 \pm 2.26$ & $11.78 \pm 2.30$ \\
\hline & $\mathrm{BBM}-\mathrm{N} / \mathrm{L}_{200}$ & $14.25 \pm 3.01$ & $13.58 \pm 2.68$ \\
\hline & $\mathrm{BBM}+\mathrm{N} / \mathrm{L}_{200}$ & $13.72 \pm 2.35$ & $13.86 \pm 1.74$ \\
\hline \multirow{4}{*}{ T. obliquus } & $\mathrm{BBM}-\mathrm{N} / \mathrm{L}_{120}$ & $13.84 \pm 2.10$ & $16.18 \pm 2.41$ \\
\hline & $\mathrm{BBM}+\mathrm{N} / \mathrm{L}_{120}$ & $16.23 \pm 3.26$ & $15.21 \pm 1.28$ \\
\hline & $\mathrm{BBM}-\mathrm{N} / \mathrm{L}_{200}$ & $18.93 \pm 2.27$ & $18.28 \pm 3.20$ \\
\hline & $\mathrm{BBM}+\mathrm{N} \mathrm{L} 200$ & $18.77 \pm 3.14$ & $15.27 \pm 2.64$ \\
\hline \multirow{4}{*}{ D. abundans } & BBM-N/L 120 & $5.85 \pm 1.44$ & $5.48 \pm 1.08$ \\
\hline & $\mathrm{BBM}+\mathrm{N} / \mathrm{L}_{120}$ & $6.33 \pm 1.42$ & $5.20 \pm 1.15$ \\
\hline & $\mathrm{BBM}-\mathrm{N} / \mathrm{L}_{200}$ & $6.71 \pm 1.54$ & $8.13 \pm 1.27$ \\
\hline & $\mathrm{BBM}+\mathrm{N} / \mathrm{L}_{200}$ & $6.32 \pm 1.32$ & $6.58 \pm 1.16$ \\
\hline \multirow{4}{*}{ D. communis } & BBM-N/L 120 & $22.74 \pm 2.37$ & $20.16 \pm 2.63$ \\
\hline & $\mathrm{BBM}+\mathrm{N} / \mathrm{L}_{120}$ & $22.76 \pm 1.68$ & $19.13 \pm 2.42$ \\
\hline & $\mathrm{BBM}-\mathrm{N} / \mathrm{L}_{200}$ & $21.81 \pm 3.65$ & $21.65 \pm 2.96$ \\
\hline & $\mathrm{BBM}+\mathrm{N} / \mathrm{L}_{200}$ & $21.23 \pm 2.40$ & $20.87 \pm 2.64$ \\
\hline \multirow{4}{*}{ D. opoliensis } & $\mathrm{BBM}-\mathrm{N} / \mathrm{L}_{120}$ & $29.14 \pm 3.08$ & $29.88 \pm 1.89$ \\
\hline & $\mathrm{BBM}+\mathrm{N} / \mathrm{L}_{120}$ & $27.65 \pm 3.69$ & $24.02 \pm 2.55$ \\
\hline & $\mathrm{BBM}-\mathrm{N} / \mathrm{L}_{200}$ & $21.55 \pm 1.88$ & $29.07 \pm 1.68$ \\
\hline & $\mathrm{BBM}+\mathrm{N} / \mathrm{L}_{200}$ & $24.49 \pm 2.42$ & $24.17 \pm 2.35$ \\
\hline
\end{tabular}

All the strains investigated appeared green in color (Figure $3 a, c, e)$ in presence of the nitrogen source $(B B M+N)$ while the nitrogen starvation induced a shift to a yellow green color of the cells in all the cultures grown in BBM-N (Figure $3 b, d, f)$. The change in color was a clear effect of the stress conditions induced by N-limitation. This triggers many metabolic responses in microalgae, such as the degradation of nitrogenous compounds like proteins, chlorophyll, DNA, etc. and accumulation of energy rich compounds like lipids and carbohydrates $[10,14]$.

To evaluate lipid accumulation, the use of staining dyes (e.g., Nile red, BODIPY) offer a rapid analysis tool for a qualitative estimation of neutral lipid content, avoiding time-consuming and costly gravimetric analyses [41,42]. Confocal Laser Scanning Microscope (CLSM) observations of lipid droplets in microalgal cells after Nile red staining were performed on the culture of $D$. abundans that showed the highest yield of FAME. In cultures grown in BBM+N both at $\mathrm{L}_{120}$ and $\mathrm{L}_{200}$, cells appeared red in color due to the autofluorescence of chlorophyll and just a few lipid droplets, identified by their yellow color, were visible (Figure 4a,g, respectively). By contrast, when D. abundans was grown in BBM-N, cultures showed evident yellowish spots inside cells due to the presence of neutral lipids, both in $\mathrm{L}_{120}$ and $\mathrm{L}_{200}$ conditions (Figure $4 \mathrm{~d}$,j, respectively). With the confocal microscopy, the analysis of the in vivo fluorescence spectra in small detection areas can be investigated, so that single cells can be studied in vivo using a noninvasive technique for obtaining qualitative information [43]. In this study, the spectral analysis was performed in selected Regions Of Interest (ROI) representing single cells or subcellular regions (Figure $4 \mathrm{~b}, \mathrm{e}, \mathrm{h}, \mathrm{k}$ ) to evaluate the maximum emission intensity of Nile 
red (between 580 and $600 \mathrm{~nm}$ ) in correspondence of lipid granules. As indicated in Figure $4 \mathrm{e}, \mathrm{f}, \mathrm{k}, 1$ ( $\mathrm{ROI}=4$ and $\mathrm{ROI}=1$, respectively) in N-depleted lipid-rich cells the emission peaks corresponded to Nile red fluorescence, while in cells grown in complete medium that resulted without evident lipid droplets (Figure $4 b, c, h, i, R O I=3$ ) the emission peaks corresponded to pigment autofluorescence ( 505 to $670 \mathrm{~nm}$ ) of chlorophyll $a$. These results are in line with those reported by Gusbhet et al. [44] that observed a specific emission peak at $598 \mathrm{~nm}$-when excited at $495 \mathrm{~nm}$-in Nile red stained cells of Auxenochlorella protothecoides, while both stained and unstained cells also have an emission peak of $678 \mathrm{~nm}$, due to the autofluorescence of chlorophyll $a$. Tracking the increase in lipid content during the growth of microalgae represents a useful tool that could contribute to the cost reduction needed to reach the goal of the sustainable and economical production of biodiesel [45]. Different authors [41,46] described some quantitative protocols that exploit the possibility to correlate total lipids content with cell fluorescence, using fluorimetry and/or spectrometry methodologies.
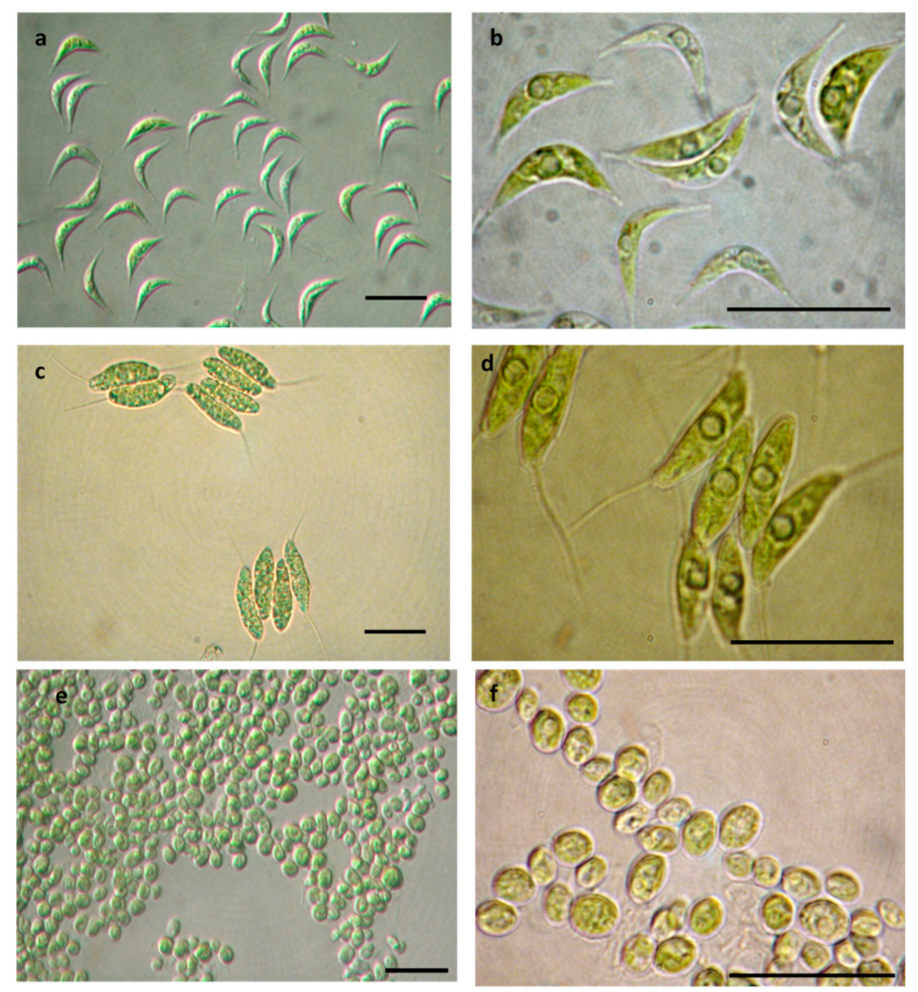

Figure 3. Light microscopy (LM) observations of S. acuminatus SAG 38.81 grown in BBM+N/L 200 (a) at the start and (b) at stationary phase; D. abundans ACUF 283/1.8 in BBM+N/L 200 (c) at the start and (d) at stationary phase; D. opoliensis SAG 64.94 in BBM-N/L 120 (e) at the start and (f) at stationary phase. bar $=10 \mu \mathrm{m}$. 

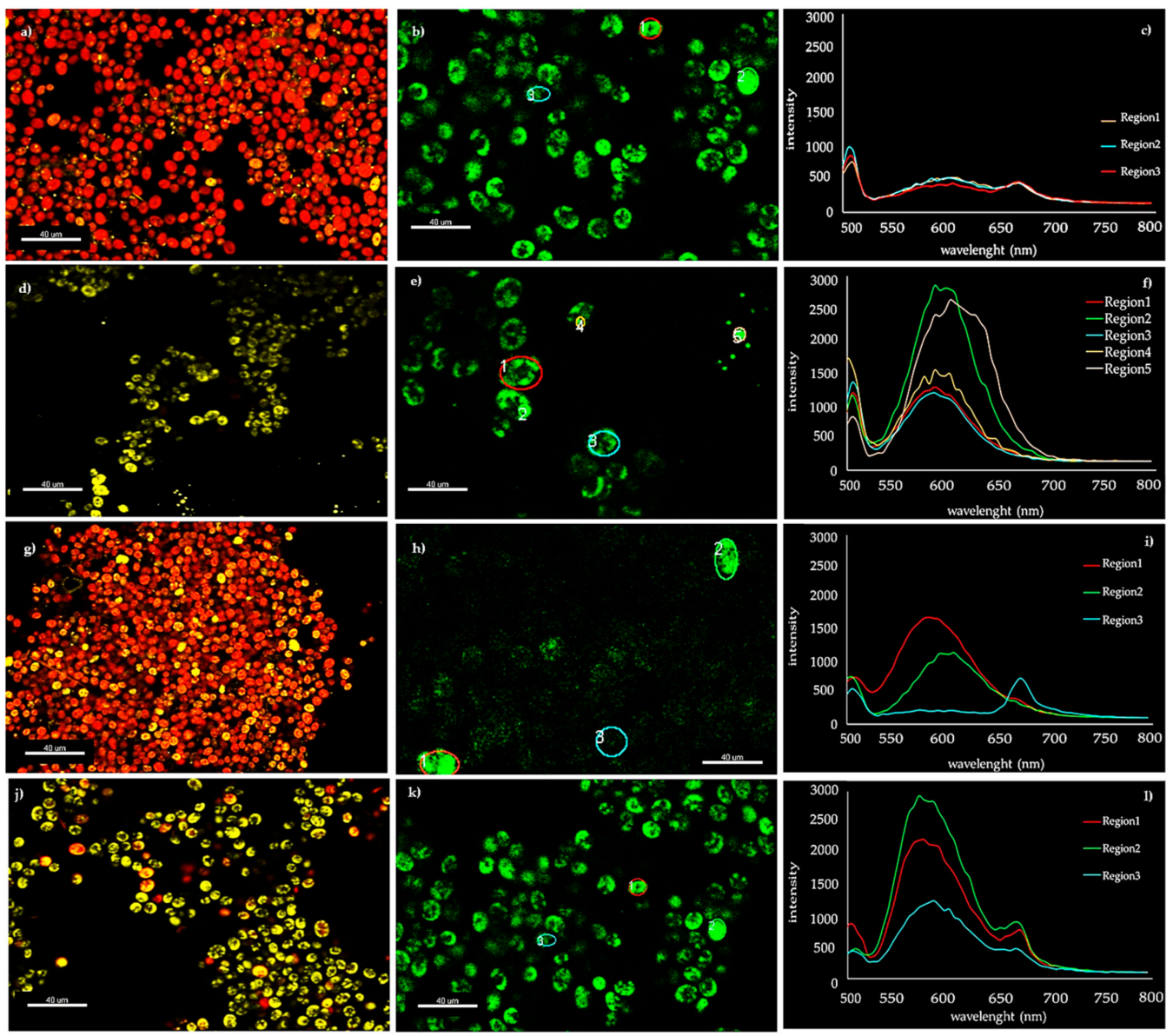

Figure 4. Confocal laser scanning microscope (CLSM) observations of Desmodesmus abundans. (a-c) cells grown in $\mathrm{BBM}+\mathrm{N} / \mathrm{L}_{120} ;(\mathbf{d}-\mathbf{f})$ cells grown in BBM-N/L $\mathrm{L}_{120} ;(\mathbf{g}-\mathbf{i})$ cells grown in $\mathrm{BBM}+\mathrm{N} / \mathrm{L}_{200} ;(\mathbf{j}-\mathbf{l})$ cells grown in BBM-N/L 200 . Colored circles in $(\mathbf{b}, \mathbf{e}, \mathbf{h}, \mathbf{k})$ represent the regions of interest (ROI) of interest (from 1 to 5 ) studied by spectral analyses in the scan visible region $(\mathbf{c}, \mathbf{f}, \mathbf{i}, \mathbf{l})$.

\subsection{Multivariate Analysis}

A principal component analysis (PCA) was performed on a dataset of 27 observations (all the strains in all culture conditions) and 4 variables (dry weight of the biomass, biomass production, lipid yield and FAME) (Figure 5). The PCA allowed to ordinate the observations in a biplot evidencing the treatment groups with existing correlation among the original variables. The first Axis (PC1) explained 52.5\% and the second axis (PC2) $21.4 \%$ of the variance. Therefore, the two-axis ordination biplot described $73.9 \%$ of the total variance. Harvested biomass was negatively correlated with FAME and lipid yield and all provided the heaviest loading on axis 1 while the biomass production was negatively correlated with lipid yield having the heaviest loading on axis 2 . Axis 1 separated PCAs and clearly discriminated between the BBM+N and BBM-N. All observations for cultures grown in BBM-N were located on the right-hand side of the graph, indicating high FAME and lipid yields and low biomass production in these culture conditions. Instead, observations related to cultures grown in $\mathrm{BBM}+\mathrm{N}$, were located on the left of the graph, characterized by high biomass production with a low FAME and lipid yields. The PCAs, however, failed to clearly discriminate between $\mathrm{L}_{120}$ and $\mathrm{L}_{200}$ conditions confirming that the two light irradiances used in this work were unable to induce significant differences in the growth and lipid production of these strains. 


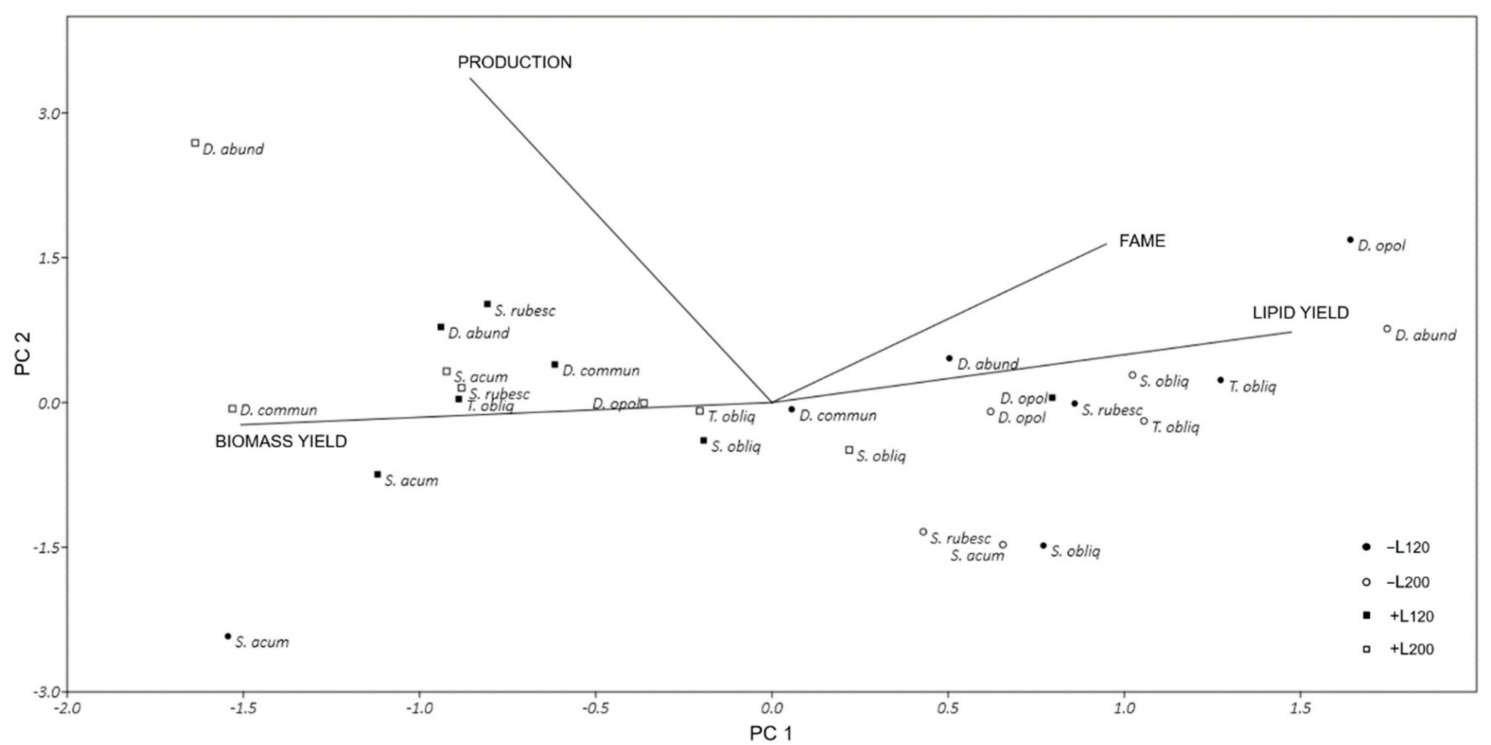

Figure 5. Principal component analysis (PCA) performed on a correlation matrix evidencing the relationships among observations (all the strains in all culture conditions) and variables. Biomass means dry weight as grams; production means biomass production as gDW L ${ }^{-1}$; lipid yield and FAME expressed as \%. - /+ indicated the absence/presence of $\mathrm{N}$ in BBM medium.

\section{Conclusions}

In this study, seven strains of green microalgae were evaluated in terms of biomass productivity, FAME yields and biodiesel properties. T. obliquus and all the species of Desmodesmus genus, showed the highest biomass production in the tested growth conditions, when grown in BBM+N at $200 \pm 20 \mu \mathrm{mol}$ photons $\mathrm{m}^{-2} \mathrm{~s}^{-1}$ of light intensity. The highest biomass production for T. obliquus also corresponded to high FAME yield (up to $23 \%$ ), while among the Desmodesmus genus, D. opoliensis and D. abundans showed a FAME yield between $25 \%$ and $35 \%$ in BBM-N/L 200 . FAME profile characterization of T. obliquus and D. abundans demonstrated that saturated fatty acids (SFAs) were over $90 \%$ of total FAME and were rich in C16:0 and C18:0 that favors better viscosity and the applicability of a good quality biodiesel at low temperatures. The accordance of biodiesel properties obtained here with European biodiesel (EN 14,214) and American biodiesel standards (ASTM D 6751-08), also reinforced the suitability of these microalgae for the production of lipids capable of fulfilling all the requirements for a top-quality biodiesel. Moreover, evaluation of cell morphology and size-increase represents a reliable way of monitoring the cell culture conditions when exposed to stressing conditions such as nitrogen starvation. This, coupled with the observation of the increase in fluorescence intensity of lipid droplets in stained cells of $D$. abundans, after some days following the nitrogen starvation, suggested the possibility of evaluating lipid accumulation in vivo over time, in order to better estimate maximum lipid production before the direct extraction of these compounds. Therefore, T. obliquus and D. abundans seem to be promising candidates for further studies on their applicability as an alternative sustainable and renewable source of biofuels.

Supplementary Materials: The following are available online at http://www.mdpi.com/2076-2607/8/8/1254/s1, Figure S1: Growth curves of the strains belonging to the genera Scenedesmus and Tetradesmus; Figure S2: Growth curves of the strains belonging to the genera Desmodesmus.

Author Contributions: Conceptualization, L.B. and S.A.; validation, L.R., C.R., S.A., A.R. and L.B.; formal analysis, L.R., C.R. and S.A.; data curation, L.R., C.R., S.A. and L.B.; writing-original draft preparation, L.R., C.R. and L.B.; writing-review and editing, L.R., S.A., A.R. and L.B.; funding acquisition, L.R. and L.B. All authors have read and agreed to the published version of the manuscript.

Funding: This research was partially funded by the project '85-2017-15096-BEEP-Algal biomass as source of energy and pigments' Lazio Region Call: 'Research Group Projects-Knowledge e cooperation for a new development model' R.L. 13/2008. 
Acknowledgments: The authors gratefully thank Elena Romano of the Center of Advanced Microscopy (CAM) 'P. Albertano', Department of Biology, University of Rome "Tor Vergata" for her assistance in the use of the facility and the ACUF (Algal Collection University Federico II) that kindly gave to the Laboratory of Biology of Algae the strain D. abundans $283 / 1.8$ used in this study.

Conflicts of Interest: The authors declare no conflict of interest.

\section{References}

1. Arora, N.; Tripathi, S.; Pruthi, P.A.; Poluri, K.M.; Pruthi, V. Assessing the robust growth and lipid-accumulating characteristics of Scenedesmus sp. for biodiesel production. Environ. Sci. Pollut. Res. 2019. [CrossRef] [PubMed]

2. Maity, J.P.; Bundschuh, J.; Chen, C.Y.; Bhattacharya, P. Microalgae for third generation biofuel production, mitigation of greenhouse gas emissions and wastewater treatment: Present and future perspectives-A mini review. Energy 2014, 104-113. [CrossRef]

3. Ghorbani, A.; Rahimpour, M.R.; Ghasemi, Y.; Raeissi, S. The biodiesel of microalgae as a solution for diesel demand in Iran. Energies 2018, 11, 950. [CrossRef]

4. Nzayisenga, J.C.; Farge, X.; Groll, S.L.; Sellstedt, A. Effects of light intensity on growth and lipid production in microalgae grown in wastewater. Biotechnol. Biofuels 2020, 13. [CrossRef]

5. Ramos, M.J.; Fernàndez, C.M.; Casa, A.; Rodrìguez, L.; Pérez, A. Influence of fatty acid composition of raw materials on biodiesel properties. Bioresour. Technol. 2009, 100, 261-268. [CrossRef] [PubMed]

6. Mata, T.M.; Martins, A.A.; Caetano, N.S. Microalgae for biodiesel production: A mini-review. Renew. Sustain. Energy Rev. 2010, 14, 217-232. [CrossRef]

7. Akgul, F. Effects of nitrogen concentration on growth, biomass, and biochemical composition of Desmodesmus communis (E. Hegewald) E. Hegewald. Prep. Biochem. 98-105. [CrossRef]

8. Rugnini, L.; Costa, G.; Congestri, R.; Antonaroli, S.; Sanità di Toppi, L.; Bruno, L. Phosphorus and metal removal combined with lipid production by the green microalga Desmodesmus sp.: An integrated approach. Plant. Physiol. Biochem. 2018, 125, 45-51. [CrossRef]

9. Hernandez-Garcia, A.; Velasquez-Orta, S.B.; Novelo, E.; Yanez-Noguez, I.; Monje-Ramirez, I.; Orta Ledesma, M.T. Wastewater-leachate treatment by microalgae: Biomass, carbohydrate and lipid production. Ecotoxico. Environ. Saf. 2019, 174, 435-444. [CrossRef]

10. Aratboni, H.; Rafiei, N.; Garcia-Granados, R.; Alemzadeh, A.; Morones-Ramírez, J.R. Biomass and lipid induction strategies in microalgae for biofuel production and other applications. Microb. Cell Factories 2019, 18, 178. [CrossRef]

11. Zhu, L.; Li, Z.; Hiltunen, E. Strategies for lipid production improvement in microalgae as a biodiesel feedstock. Biomed. Res. Int. 2016, 8. [CrossRef]

12. Gouveia, L.; Oliveira, A.C.; Congestri, R.; Bruno, L.; Soare, A.T.; Menezes, R.S.; Filho, N.R.A.; Tzoveni, I. Biodiesel from microalgae. In Microalgae-Based Biofuels and Bioproducts, from Feedstock Cultivation to End-Products; Gonzalez-Fernadez, C., Munoz, R., Eds.; Woodhead Publishing Series in Energy: Duxford, UK, 2017.

13. Pancha, I.; Chokshi, K.; George, B.; Ghosh, T.; Paliwal, C.; Maurya, R.; Mishra, S. Nitrogen stress triggered biochemical and morphological changes in the microalgae Scenedesmus sp. CCNM 1077. Bioresour. Technol. 2014, 156, 146-154. [CrossRef] [PubMed]

14. Griffith, M.J.; Van Hille, R.P.; Harrison, S.T.L. Lipid productivity, settling potential and fatty acid profile of 11 microalgal species grown under nitrogen replete and limited conditions. J. Appl. Phycol. 2012, 24, 989-1001. [CrossRef]

15. Nascimento, I.A.; Marques, S.S.I.; Cabanelas, I.T.D.; Pereira, S.A.; Druzian, J.I.; de Souza, C.O.; Vich, D.V.; de Carvalho, G.C.; Nascimento, M.A. Screening microalgae strains for biodiesel production: Lipid productivity and estimation of fuel quality based on fatty acids profiles as selective criteria. Bioenerg. Res. 2013, 6, 1-13. [CrossRef]

16. Gouveia, L.; Oliveira, A.C. Microalgae as raw material for biofuels production. J. Ind. Microbiol. Biotechnol. 2009, 6, 269-274. [CrossRef] [PubMed]

17. Rugnini, L.; Elwood, N.T.W.; Costa, G.; Falsetti, A.; Congestri, R.; Bruno, L. Scaling-up of wastewater bioremediation by Tetradesmus obliquus, sequential bio-treatments of nutrients and metals. Ecotoxicol. Environ. Saf. 2019, 172, 59-64. [CrossRef] 
18. Castenholz, R.W. Cyanobacteria. Oxygenic photosynthetic bacteria. In Bergey's Manual of Systematic Bacteriology, 2nd ed.; Springer: New York, NY, USA, 2001; pp. 473-487.

19. Starr, R.C.; Zeikus, J.A. UTEX-The culture collection of algae at the University of Texas at Austin. J. Phycol. 1987, 29, 1-106. [CrossRef]

20. Bannon, C.D.; Breen, G.J.; Craske, J.D.; Trong, H.N.; Harper, N.L.; O’Rourke, K.L. Analysis of fatty acid methyl esters with high accuracy and reliability. iii. Literature review of and investigations into the development of rapid procedures for the methoxide-catalysed methanolysis of fats and oils. J. Chrom A 1982, 247, 71-89. [CrossRef]

21. Schneider, C.A.; Rasband, W.S.; Eliceiri, K.W. NIH Image to ImageJ: 25 years of image analysis. Nat. Methods 2012, 9, 671-675. [CrossRef]

22. Greenspan, P.; Fowler, S.D. Spectrofluorometric studies of the lipid probe, nile red. J. Lipid Res. 1985, 26, 781-789.

23. Hammer, Ø.; Harper, D.A.; Ryan, P.D. PAST: Paleontological statistics software package for education and data analysis. Palaeontol. Electron. 2001, 4, 9.

24. Sforza, E.; Gris, B.; de Farias Silva, C.E.; Morosinotto, T.; Bertucco, A. Effects of light on cultivation of Scenedesmus Obliquus in batch and continuous flat plate photobioreactor. Chem. Eng. Trans. 2014, 38, 211-216.

25. Wu, Y.H.; Yu, Y.; Hu, H.Y. Effects of initial phosphorus concentration and light intensity on biomass yield per phosphorus and lipid accumulation of Scenedesmus sp. LX1. Bioenergy Res. 2014. [CrossRef]

26. Han, S.F.; Jin, W.; Abomohra., A.E.F.; Tu, R.; Zhou, X.; He, Z.; Chen, C.; Xie, G. Municipal wastewater enriched with trace metals for enhanced lipid production of the biodiesel-promising microalga Scenedesmus obliquus. BioEnergy Res. 2019. [CrossRef]

27. Maheshwari, N.; Krishna, P.K.; Thakur, I.S.; Srivastava, S. Biological fixation of carbon dioxide and biodiesel production using microalgae isolated from sewage waste water. Environ. Sci. Pollut. Res. 2019, 1-11. [CrossRef] [PubMed]

28. Lang, I.; Hodac, L.; Friedl, T.; Feussner, I. Fatty acid profiles and their distribution patterns in microalgae: A comprehensive analysis of more than 2000 strains from the SAG culture collection. BMC Plant. Biol. 2011, 11, 124. [CrossRef] [PubMed]

29. Quintana, N.; Van der Kooy, F.; Van de Rhee, M.D.; Voshol, G.P.; Verpoorte, R. Renewable energy from Cyanobacteria: Energy production optimization by metabolic pathway engineering. Appl. Microbiol. Biotechnol. 2011, 91, 471-490. [CrossRef]

30. Bruno, L.; Di Pippo, F.; Antonaroli, S.; Gismondi, A.; Valentini, C.; Albertano, P. Characterization for biofilm-forming cyanobacteria for biomass and lipid production. J. Appl. Microbiol. 2012, 113, 1052-1064. [CrossRef]

31. Mandotra, S.K.; Kumar, P.; Suseela, M.R.; Ramteke, P.W. Fresh water green microalga Scenedesmus abundans: A potential feedstock for high quality biodiesel production. Bioresour. Technol. 2014, 156, 42-47. [CrossRef]

32. Pereira, H.; Barreira, L.; Custódio, L.; Alrokayan, S.; Mouffouk, F.; Varela, J.; Abu-Salah, K.M.; Ban-Hamadou, R. Isolation and fatty acid profile of selected microalgae strains from the Red sea for biofuel production. Energies 2013, 6, 2773-2783. [CrossRef]

33. eur-lex.europa.eu. Available online: https://eur-lex.europa.eu/LexUriServ/LexUriServ.do?uri=OJ:L:2003:123: 0042:0046:EN:PDF (accessed on 20 July 2020).

34. ASTM. Standard specification for biodiesel fuel (B100) blend stock for distillate fuels. In Annual Book of ASTM Standard, Method D6751; ASTM International: West Conshohocken, PA, USA, 2008.

35. Vishwakarma, R.; Dhar, D.W.; Saxena, S. Influence of nutrient formulations on growth, lipid yield, carbon partitioning and biodiesel quality potential of Botryococcus sp. and Chlorella sp. Environ. Sci. Pollut. Res. 2019, 26, 7589-7600. [CrossRef] [PubMed]

36. Gismondi, A.; Di Pippo, F.; Bruno, L.; Antonaroli, S.; Congestri, R. Phosphorus removal coupled to bioenergy production by three cyanobacterial isolates in a biofilm dynamic growth system. Int. J. Phytoremediation 2016, 18, 869-876. [CrossRef] [PubMed]

37. Komarek, J.; Foot, B. Chlorophyceae (Grünalgen), Ordung: Chlorococcales. In Das Phytoplankton des Sübwassers: Systematik und Biologie; Huber-Pestalozzi, G., Ed.; E. Schweizerbart'sche Verlagsbuchlandlung (Nägele u. Obermiller): Stuttgart, Germany, 1983; pp. 1-1044.

38. Lurling, M. Phenotypic plasticity in the green algae Desmodesmus and Scenedesmus with special reference to the induction of defensive morphology. Ann. Limnol. Int. J. Lim. 2003, 39, 85-101. [CrossRef] 
39. El Semary, N.A. The polyphasic description of a Desmodesmus spp. Isolate with the potential of bioactive compounds production. Biotechnol. Agron. Soc. Environ. 2011, 15, 231-238.

40. Yap, B.H.J.; Crawford, S.A.; Dagastine, R.R. Nitrogen deprivation of microalgae: Effect on cell size, cell wall thickness, cell strength, and resistance to mechanical disruption. J. Ind. Microbiol. Biotechnol. 2016, 43, 1671-1680. [CrossRef]

41. Rumin, J.; Bonnefond, H.; Saint-Jeane, B.; Rouxel, C.; Sciandra, A.; Bernard, O.; Cadoret, J.P.; Bougaran, G. The use of fluorescent Nile red and BODIPY for lipid measurement in microalgae. Biotechnol. Biofuels 2015, 8, 42. [CrossRef]

42. Sharma, J.; Kumar, S.K.; Bishnoi, N.R.; Pugazhendhi, A. Screening and enrichment of high lipid producing microalgal consortia. J. Photochem. Photobiol. B Biol. 2019, 192, 8-12. [CrossRef]

43. Roldàn, M.; Thomas, F.; Castel, S.; Quesada, A.; Hernàndez-Mariné, M. Non-invasive pigment identification in single cells from living phototrophic biofilms by confocal imaging spectrofluorometry. Appl. Environ. Microbiol. 2004, 70, 3745-3750. [CrossRef]

44. Gusbeth, C.A.; Eing, C.; Göttel, M.; Sträßner, R.; Wolfgang, F. Fluorescence diagnostics for lipid status monitoring of microalgae during cultivation. Int. J. Renew. Energy Biofuels 2016, 899698. [CrossRef]

45. Ravindran, B.; Gupta, S.K.; Cho, W.-M.; Kim, J.K.; Lee, S.R.; Jeong, K.-H.; Lee, D.J.; Choi, H.-C. Microalgae potential and multiple roles-Current progress and future prospects-An overview. Sustainability 2016, 8, 1215. [CrossRef]

46. De la Hoz Siegler, H.; Ben-Zvi, A.; McCaffrey, W.C. Improving the reliability of fluorescence-based neutral lipid content measurements in microalgal cultures. Algal Res. 2012, 1, 176-184. [CrossRef]

(C) 2020 by the authors. Licensee MDPI, Basel, Switzerland. This article is an open access article distributed under the terms and conditions of the Creative Commons Attribution (CC BY) license (http://creativecommons.org/licenses/by/4.0/). 